\title{
Organizational Citizenship Behavior and Faculty Mindset Amidst Professional Development Activities
}

\section{Kristen Ferris, University of New Mexico}

Kristen Ferris is a student in the Organization, Information, and Learning Sciences program at the University of New Mexico. Her research interests include faculty mindset change, change management, and organizational citizenship behavior. Much of her research is part of a National Science Foundation grant at UNM where the chemical and biological engineering department is redesigning curriculum to support diverse student retention and graduation. She intends to further her knowledge in the field of change management and hopes to study social network analyses of higher education organizations undergoing change to track buy-in, barriers, and adoption.

\section{Dr. Vanessa Svihla, University of New Mexico}

Dr. Vanessa Svihla is a learning scientist and associate professor at the University of New Mexico in the Organization, Information \& Learning Sciences program and in the Chemical \& Biological Engineering Department. She served as Co-PI on an NSF RET Grant and a USDA NIFA grant, and is currently co-PI on three NSF-funded projects in engineering and computer science education, including a Revolutionizing Engineering Departments project. She was selected as a National Academy of Education / Spencer Postdoctoral Fellow and a 2018 NSF CAREER awardee in engineering education research. Dr. Svihla studies learning in authentic, real world conditions; this includes a two-strand research program focused on (1) authentic assessment, often aided by interactive technology, and (2) design learning, in which she studies engineers designing devices, scientists designing investigations, teachers designing learning experiences and students designing to learn.

\section{Dr. Pil Kang, University of New Mexico}

Sung "Pil" Kang is an assistant professor at the University of New Mexico. His academic interests include change management, change model validation, and mindset evolution. He may be reached at pilkang@unm.edu 


\title{
Organizational Citizenship Behavior and Faculty Mindset Amidst Professional Development Activities
}

\begin{abstract}
This research and theory paper explores the relationships between faculty mindset, participation in faculty development opportunities, and organizational citizenship behaviors (OCBs). Set in a Hispanic-serving research university engaged in a five-year change effort, the purpose of this case study is to adapt the OCB framework to higher education settings as a means to characterize how faculty participate in and benefit from professional development experiences, guided by a research question: Which OCBs are salient for understanding faculty participation in shifting from teacher-centered to learner-centered pedagogy in a chemical engineering department? We sought to investigate how OCBs related to faculty mindset and willingness to engage in professional development amidst department-wide curriculum change. Results indicated that none of the OCBs dimensions can be considered as discretionary in the higher education context because of the high degree of faculty autonomy in meeting the expectations set for tenure and promotion, and the depth and the breadth of faculty effort in teaching, scholarship, and service. Yet, OCBs provided a fruitful lens into how faculty participated in change efforts.
\end{abstract}

\section{Introduction and research purpose}

Faculty developers often see the same faculty time and time again in workshops and learning opportunities. The purpose of this case study is to adapt the OCB framework to higher education settings as a means to characterize how faculty participate in and benefit from professional development experiences. Studying faculty who willingly show up for development opportunities as well as those who are more hesitant allowed for a comparison of OCBs in each group. Specifically, guided by a research question, we sought to explore how OCBs related to faculty mindset and willingness to engage in professional development amidst department-wide curriculum change:

- Which OCBs are salient for understanding faculty participation in shifting from teachercentered to learner-centered pedagogy in a chemical engineering department?

\section{Theoretical Framework}

To explore the utility of the OCB framework in understanding faculty change, we bring together research on OCB [1] and growth mindset [2]. We argue that because higher education settings differ from the business settings in which OCBs were characterized, a focus on mindset can provide insight into ways in which specific OCBs may be indicative of change.

\section{OCBs predict positive outcomes in business settings}

Research on OCB began with the work of Bateman and Organ [3] who defined OCB as "individual behavior that is discretionary, not directly or explicitly recognized by the formal reward system, and that in aggregate promotes the effective functioning of the organization." 
Two of the early employee performance dimensions studied that were related to job satisfaction were altruism and compliance [4]. In current models based in business settings, five OCBs have been characterized and studied [5]:

- "Altruism: Discretionary behaviors that have the effect of helping a specific other with an organizationally relevant task or problem.

- Conscientiousness: Discretionary behaviors on the part of the employee that go well beyond the minimum role requirements of the organization, in the areas of attendance obeying rules and regulations, taking breaks and so forth.

- Sportsmanship: Willingness of the employee to tolerate less than ideal circumstances without complaining- to "avoid complaining, pretty grievances, railing against real or imagined slights, and making federal cases out of small potatoes."

- Courtesy: Discretionary behavior on the part of an individual aimed at preventing workrelated problems with others from occurring.

- Civic Virtue: Behavior on the part of an individual that indicates that he/she responsibly participates in, is involved in, or is concerned about the life of the company."

Employees' OCBs are related to increased job satisfaction and team commitment [3]. Analysis of survey results designed to measure $\mathrm{OCB}$ and job satisfaction for members of self-directed teams has indicated a significant relationship between the two as well as a relationship between OCB and team commitment [3]. OCB is also related to individual and group performance. Performance has been a main research interest in workplace, and the relationship between OCB and people's performance has been studied. Nielsen, Hrivnak, and Shaw [6] conducted a metaanalysis on the relationship between OCB and work performance, finding support for a positive relationship between them, especially OCB and group/team performance. These findings have made OCBs interesting as a means to understand similar issues in higher education.

\section{OCBs as collegiality in higher education}

Employees in a business organization differ in many ways from faculty in a higher education institution. In particular, faculty have a rather ill-defined scope of work. For instance, while they may know how many courses they teach, the time needed to do so is dependent on many factors, and the scope of effort tied to advisement is often an invisible component of teaching. Faculty also have a high degree of autonomy [7], within an incentive system (tenure and promotion) that privileges some forms of work over others. Yet, the idea of positive discretionary behaviors is compelling, and this led researchers to characterize OCB in higher education as collegiality.

The American Association of University Professors recommended retaining the discretionary nature of OCBs by not including collegiality as a formal part of tenure decisions [8], yet scholars have expressed a need to define standardized measures of collegiality, noting that it factors into tenure decisions in covert and subjective ways $[9,10]$. More recently, this has led to calls for better understanding of how to provide professional development related to collegiality and ways to foster collegial environments [11], in part because collegiality in higher education is positively associated with individual academic performance and organizational commitment [12]. This is similar to the effect of OCB in the workplace $[6,13]$. Research has also highlighted the merits of collegiality as one of the ways for academic departments to positively impact academic performance [12]. However, in such work, and although grounded in OCB, collegiality is 
sometimes treated as a unidimensional construct, and other times as a laundry list of actions [9, 14]. More work is needed, therefore, that explores OCBs as made visible in the process of faculty development.

\section{Faculty mindset impacts engagement in professional development}

Because we consider faculty who are change ready and change hesitant, we sought a framework to guide our understanding of these from a learning lens. We chose Dweck and Yeager's [2] characterization of fixed and growth mindsets. Fixed mindset can be described as "the belief that intelligence cannot be developed" and a growth mindset as "the belief that intelligence can be developed, for example, through personal effort, good learning strategies, and lots of mentoring" [2]. Dweck and colleagues have taken the approach that mindset is not a fixed trait but rather something that can be changed, and they have investigated interventions to provide evidence of this claim [2].

Research on these two mindsets in educational settings have indicated that fostering a growth mindset is beneficial to student learning and success [15], meaning that an instructor's beliefs affect their teaching. Hunzicker's [16] qualitative study found that teachers with a studentcentered mindset were more motivated to pursue professional growth opportunities. Faculty are also more likely to incorporate a range of instructional practices when they have inclusive beliefs - often associated with a growth mindset [17]. A longitudinal research study examined professors' beliefs about fixed student ability and the effects on student achievement. Using course evaluations researchers found that faculty mindset beliefs predict student achievement and motivation more so than any other characteristic (i.e., gender, race, age, teaching experience) [18].

Thus, a target of professional development is fostering growth mindset, and some faculty may be more or less ready for such a shift. We explore how and in what ways OCBs might facilitate this shift.

\section{Methods}

Broadly, we conducted a qualitative study to follow the progress of a major grant-funded departmental change process.

\section{Composited case study}

To protect anonymity, we composited data from multiple faculty into two cases [19]. This approach has previously been used to provide means to report on risky topics in a forthright manner [20]. Because our study focuses on change in a single engineering department, reporting on individuals as cases would present risk; in sharing data, faculty would be identifiable. We therefore formed the two cases considering faculty readiness to change, with Dr. Bora representing faculty who were change ready at the start of the project and Dr. Alban representing faculty who were change hesitant at the start of the project. We use pseudonyms and the singular they to discuss each case. 


\section{Participants \& setting}

Set in a Hispanic-serving research university engaged in a five-year change effort, our study includes both change-ready faculty and change-hesitant faculty. Change-ready faculty regularly show up to professional development workshops and show interest in applying what they learn in such workshops. Change-hesitant faculty typically do not show up at such workshops, except, perhaps, when advised to do so by a chair following poor teaching evaluations; this typically does not make them more ready to change, however. Our setting, because of the five-year effort to engage all faculty in better meeting diverse student needs, provided an opportunity to investigate both groups of faculty. Our study reports on the first four years of the project.

The departmental change effort included several strategies, guided by an engineering education researcher, to bring about change: threading design challenges through core chemical engineering courses; switching from bleed-all-over-it, long technical reports to cycles of drafts, peer and instructor feedback, and revision and reflection; and developing ways to assess and support professional skills like teamwork and mentorship. To support these changes, the department provided summer salary, peer learning facilitators (undergraduates who supported both teaching and curriculum design efforts), professional development workshops, and opportunities to collaborate on engineering education research to study the impact of changes on student learning and development.

\section{Data collection}

We collected data as audio and video recordings and field notes of faculty meetings, professional development workshops, teaching, and interviews. Of the 14 faculty members in the department, seven were interviewed during the first three years of the project. Multiple faculty were interviewed in different years of the project All interview questions were semi-structured. Interview questions sought faculty accounts of their participation in professional development opportunities provided as part of the departmental change effort and their willingness and efforts to adopt and adapt new pedagogical approaches. Follow-up prompts probed their perceptions of the impacts of these efforts.

\section{Data analysis}

We conducted qualitative analysis to first identify themes using an open coding process, followed by an adaptive coding approach [21] with the OCBs [5] and fixed and growth mindsets [2] as a framework. This involved using these as orienting concepts, then extending or splitting these as data are analyzed. By approaching that process in vivo, we grounded codes and themes in participants' own words, allowing us to construct findings in ways that stay true participants' intent and mitigate inaccurate interpretations [22]. We present the findings below for each OCB and mindset and discuss the themes we identified.

\section{Results and discussion}

We present our results, first as characterizing perspectives on students, then detailing the OCBs. 


\section{Change ready case: Dr. Bora}

Dr. Bora generally expressed a growth mindset and incorporated changes based on workshops and the overall change effort. Dr. Bora expressed interest in finding a better way to assess the diverse students in their class as part of their motivation to make changes:

I also noticed that a lot of classes that I'm teaching right now in the graduate level have a lot of really different people in it. Like there's someone who has autism and someone who has muscular dystrophy and so forth. And that's probably because of the content that I'm teaching that's unusual. But it's also I think more reflective of it like you know we've been trying really hard to recruit underrepresented groups and underrepresented minorities and I was like, you know I'd really like to see a different way to test people that wasn't just like you know write this down kind of stuff. And so the last thing that I did was when [a presenter] came she gave a [departmental] workshop and she was like how can we do more experimental things.

When discussing changes to their class Dr. Bora mentioned, "What I've done with all three of them is tried to adjust them so that they have more project development as part of the class." They also mentioned implementing changes based on a workshop conversation:

And during the workshop people talked about well you could give a two part test where the first half is like a take home that they have to work on by themselves and then they come in and work in a team.

Dr. Bora was willing to take on the workload associated with curriculum redesign. "But what I did was I've gone to a bunch of the talks, the workshops that have been done to learn when I can." Dr. Bora's attendance at the workshops and related efforts to redesign curriculum are not due to change effort obligations. "I'm not in the team of PIs or co-PIs and I didn't go for funding for the modules."

\section{Organizational citizenship behaviors}

Altruism behaviors supported faculty like Dr. Bora to make changes. Peers helped one another and shared their successes. When asked how they supported the change effort Dr. Bora said "we" instead of "I" in their responses. When faced with a pedagogical challenge, Dr. Bora received many ideas from peers, "and then everybody starts interjecting and saying like 'Oh, have you tried this?",

Altruism behaviors were apparent in Dr. Bora's comments about their roles and understanding of how they should provide student support, as well as through their collaboration peer learning facilitators (PLFs). For example, Dr. Bora commented on developing curriculum changes:

The PLF and I came up with a way to tie together the student teams to work on a project that was related to global health and so they had a couple of interim things that they had to do like updates and [the PLF] helped me design those.

Dr. Bora commented on how successful these projects were and how proud of the students they were. 
Conscientiousness behaviors were apparent in the work of faculty who were change ready. Dr. Bora showed more learner-centered teaching practices and exhibited conscientiousness through a general commitment to hard work. Sentiments like "redesigning the classes has definitely been more [work]" express that faculty saw the work as effortful, but most faculty also saw this effort as an expected part of the work, explaining "I think they were just, you know part of being a professor and redesigning classes and stuff." Change ready faculty like Dr. Bora also indicated they made more changes to curriculum inspired by a professional development workshop.

Civic virtue behaviors were first apparent in change-ready faculty like Dr. Bora. In addition to their more frequent attendance at workshops, they also made more positive comments about the departmental change project, reflecting civic virtue. Dr. Bora often participated in workshops even if they did not directly relate to their interests, "Well, we go to the workshops and some of them are more helpful to me than others. Like I said, the one with [a specific presenter] was-is really, really good."

\section{Change hesitant case: Dr. Alban}

Over the course of several years, Dr. Alban began to show more evidence of a growth mindset, although they still used many instructor-centered teaching approaches. Dr. Alban understood the need for change, however, and linked this to the diversity of students: "When you have a diverse group of students...I think we could do a better job, and this certainly brought to focus how little we know about different cultures as an instructor." Dr. Alban seemed unsure how to tell if their instruction supported students to build on their everyday and cultural assets - a central focus of the change efforts - explaining, "I don't know how you can bring that out" and "I don't know what sort of background they have, and how that's contributing to solving these problems." Dr. Alban also mentioned students want "to have this traditional line of teaching, which is lectures and seminars and recitations and homework, and I see the value in that too." This highlights a tension faculty like Dr. Alban experience as they encounter their own hesitancy and student resistance to change.

Dr. Alban attended professional development workshops given to support faculty to make changes, and we see that they learned specific guidelines from these. For instance, they explained, "I also learned that the composition of each team makes a huge difference and it's not necessarily their individual academic strength." Dr. Alban did not always implement changes based on the workshops. When asked about this, they said, "Well, I didn't do any curriculum changes based on that." When asked to elaborate on why the workshops did not have an impact they said, "Well, I think that the design uh project that we have was enough to change," referring to design challenge that they introduced. Dr. Alban also noted that "I really truly believe that teaching can only improve. There are many things that don't know pedagogically what really works with students." Thus, while Dr. Alban did introduce a design challenge - one of the main changes the project focused on, they retained some uncertainty about how students learn.

\section{Organizational citizenship behaviors}

Dr. Alban displayed conscientiousness behaviors, but much later in the change effort than Dr. Bora. Initially, Dr. Alban showed less willingness to participate, "I was kind of dragged onto the team." By year three, when talking about the workload related to the change effort, these faculty 
members said similar comments to the change ready faculty such as, "It's teaching, teaching is teaching."

Examples of poor sportsmanship were evident at the start of the project when Dr. Alban did not want to participate or commit time to the project for fear it would be replaced with something else. Comments like it "take[s] me away from my comfort zone, which is lecturing" and "I need to be convinced that this is a sustainable effort" are examples of this. These issues were resolved through courteous behaviors from Dr. Bora as evident by comments like this:

I feel like without this cohort of colleagues who are making changes ... and that person giving me ideas about how I could make these changes, I don't think I would have made it, right? ... It definitely kind of, you know, kinda moved that inertia into change, into thinking, oh yeah, I could do this.

Dr. Alban's civic virtue behaviors were less apparent early on and they were less enthusiastic about the project and its usefulness. When asked about the usefulness of workshops Dr. Alban replied, "I frankly don't have a recollection." Influenced by the civic virtue behaviors of others Dr. Alban began to exhibit their own civic virtue behaviors later in the project. When speaking about the curriculum changes in year three Dr. Alban said, "so there are aspects of it that I like quite a lot" and "people are willing to participate in this."

\section{Cross Case Analysis and Significance}

Faculty mindsets appear to have shifted from fixed to growth mindsets, although at different rates. Comments from change hesitant faculty that referenced students' innate abilities such as, "some students are very much, can't, I don't want to say born with it, but there are some natural engineers with a good, good cognitive perception," were more common early in the project. Compared to early interviews Dr. Alban has begun to make fewer comments that suggest they hold a fixed mindset, such as "top undergraduate students deserve a world class experience" and "she's not a great student." They also made comments that showed signs of a growth mindset. When talking about what they have learned at workshops Dr. Alban said,

I think a couple of things. One is cultural awareness, and the effects of group composition...but the students who are not necessarily high performing students in the class, when they're put together, they did better than the group with a bunch of high performing students.

Dr. Bora often discussed diverse student academic abilities and backgrounds, suggesting a growth mindset. For example, they explained, "I am having them work in teams, because again, I've got this wide disparity of abilities and, um, some people have done other classes where they have design and some haven't" and "these students who are not traditionally good students have really been able to do well on these questions and I made the assignments such that everybody sees that in the class."

Collaboration was a common theme across all faculty and collaborative efforts grew over time. Specific curriculum changes were influenced by peers. As one faculty stated regarding their early changes, "It was suggested by a colleague of mine." Three years into the change efforts, collaboration involved larger groups of peers. For example, when discussing how a successful 
change came about during a group discussion at professional development workshop, "That was really helpful. We hadn't really had that kind of an interactive style before, I really like that." Faculty members also discussed how they have learned from peers "so that was really helpful because I had thought there was like one perfect way and they basically said as long as not everybody choosing their own team it's fine." Additionally, poor sportsmanship behaviors of Dr. Alban were mitigated by collaboration with Dr. Bora.

Based on attendee lists from the workshops, change ready faculty like Dr. Bora participated in workshops more often than change hesitant faculty like Dr. Alban. Both groups of faculty mentioned that one of the key factors affecting their attendance was related to scheduling. When asked about how they decided which workshops to attend they responded, "a lot of it is based on if I'm here (laugh) because I have a lot of travel this semester" and "it's just based on when they do it."

Observation of others' success helped influence additional faculty participation and may be useful for encouraging more workshop participation. For example, when asked what influenced participation in faculty development project change ready faculty responded, "I've watched [a faculty] totally change how she teaches her classes and how she sets up her teams and stuff and how much, I know that it's more successful with her students." There were also comments such as, "those two have been really good role models for me" that support promoting successful aspects of the change effort.

Our analysis first clarified that none of the OCBs can truly be considered as "discretionary, not directly or explicitly recognized by the formal reward system" [1] in the higher education context because of the high degree of faculty autonomy in meeting the expectations set for tenure and promotion, and the depth and the breadth of faculty effort in teaching, scholarship, and service. Yet, we found evidence of OCBs. Altruism was visible in early faculty comments about their roles. Civic virtue was apparent in the change-ready faculty, and the change-hesitant faculty later picked up this behavior, seeing both the hard work (conscientiousness) and success of the change-ready faculty. Poor sportsmanship negatively impacted the project early but was resolved through courteous behaviors. We therefore found OCB provided a fruitful lens into how faculty participated in change efforts.

Our study aligns to previous work suggesting that all five OCBs are applicable in higher education $[1,5]$. In contrast, collegiality is often measured as unidimensional [12]. Our research highlights ways the five OCBs can be behavioral indicators of collegiality, which are aligned with assertions in the previous studies [9, 23].

Furthermore, our research shows that OCB as collegiality influences faculty mindset for curricular and instructional changes in engineering education. We found that faculty with high OCB committed more to the change initiatives and actively engaged in efforts to develop and implement student-centered teaching strategies. Our study therefore expands Su and Baird's research [12]. They found that collegiality increases faculty commitment and that increased commitment can improve faculty teaching. In our research, faculty mindset towards students (growth vs. fixed mindset) intersected with OCBs in ways that can directly influence both student-centered teaching and participation in departmental change efforts. Notably, altruism and 
civic virtue behaviors become more common as student-centered teaching practices increase. We found that these in turn fostered increased willingness to participate in the change effort.

\section{Limitations \& future work}

Using OCB as part of the framework also introduced a few issues. It can sometimes be difficult to generalize or even transfer findings of OCB research to settings with different contexts. For instance, our context involved a major grant-funded departmental change process at a Hispanicserving research university. Our results may not be generalizable to contexts in which there are no other strong drivers for collective change. Likewise, our cultural context differentiates both our students and faculty.

Limitations of the study stem from the purposeful sampling of faculty who were members of a department that was engaged in a change effort. Although our study included faculty on the core team guiding the change as well as faculty who were more hesitant to contribute, we did not include faculty from other programs and part time faculty who contributed to teaching. In our case, this typically amounted to just one or two courses per year, often as a means to cover courses for faculty on sabbatical or courses shared between programs. Future research, however, should also seek out the points of view of part-time and contingent faculty, especially as many departments rely heaving on such faculty for undergraduate courses. Likewise, our research focused deeply on a single department. While this provided an opportunity to understand OCBs in practice, it did not provide sufficient contrast to characterize the roles administrators may play in this process. Therefore, it may be useful to look at OCBs as they relate to higher education administrators and the environment they create for faculty development.

\section{Implications}

Despite these limitations, faculty developers may find OCB useful as an approach to support their efforts by helping them identify who to engage, how and when. For example, given that we found that the change ready faculty influenced the change hesitant faculty, finding ways to pair such faculty while keeping an eye on sportsmanship may be a means to reach beyond those who "show up."

Our study covered multiple years of development. We note that faculty increased in their commitment — and this happened for both change ready and change hesitant faculty — over this long time span. Faculty developers many be frustrated when recognizing how hard and how long it can take to bring about lasting change. Our results suggest that significant change can happen, and that attending to $\mathrm{OCBs}$ and mindset can provide evidence of this developmental process.

\section{Acknowledgments}

This material is based upon work supported by the National Science Foundation under Grant No. \#1623105. Any opinions, findings, and conclusions or recommendations expressed in this material are those of the authors and do not necessarily reflect the views of the National Science Foundation. We also thank the students who participated in initial analysis efforts. 


\section{References}

[1] D. W. Organ, Organizational citizenship behavior: The good soldier syndrome. Lexington Books/DC Heath and Com, 1988.

[2] C. S. Dweck and D. S. Yeager, "Mindsets: A View From Two Eras," Perspectives on Psychological Science, vol. 14, no. 3, pp. 481-496, 2019.

[3] T. S. Bateman and D. W. Organ, "Job satisfaction and the good soldier: The relationship between affect and employee "citizenship"," Academy of Management Journal, vol. 26, pp. 587-595, 1983.

[4] C. Smith, D. W. Organ, and J. P. Near, "Organizational citizenship behavior: Its nature and antecedents," Journal of applied psychology, vol. 68, no. 4, p. 653, 1983.

[5] P. M. Podsakoff, S. B. MacKenzie, J. B. Paine, and D. G. Bachrach, "Organizational citizenship behaviors: A critical review of the theoretical and empirical literature and suggestions for future research," Journal of management, vol. 26, no. 3, pp. 513-563, 2000.

[6] T. M. Nielsen, G. A. Hrivnak, and M. Shaw, "Organizational citizenship behavior and performance: A meta-analysis of group-level research," Small Group Research, vol. 40, no. 5, pp. 555-577, 2009.

[7] J. L. Buller, Change leadership in higher education: A practical guide to academic transformation. John Wiley \& Sons, 2015.

[8] American Association of University Professors, Policy Documents and reports. JHU Press, 2006.

[9] P. C. Johnston, T. Schimmel, and H. O'Hara, "Revisiting the AAUP Recommendation: Initial Validation of a University Faculty Model of Collegiality," College Quarterly, vol. 13, no. 2, p. n2, 2010.

[10] C. E. Schmidt, B. McNulty, S. Howard-Baptiste, and J. Harvey, "Perspectives about how to define and use collegiality in higher education," International Journal of Kinesiology in Higher Education, vol. 1, no. 1, pp. 28-34, 2017.

[11] N. Baporikar, "Collegiality as a strategy for excellence in academia," International Journal of Strategic Change Management, vol. 6, no. 1, pp. 59-72, 2015.

[12] S. Su and K. Baird, "The impact of collegiality amongst Australian accounting academics on work-related attitudes and academic performance," Studies in Higher Education, vol. 42, no. 3, pp. 411-427, 2017.

[13] W. Harwiki, "The impact of servant leadership on organization culture, organizational commitment, organizational citizenship behaviour (OCB) and employee performance in women cooperatives," Procedia-Social and Behavioral Sciences, vol. 219, no. 1, pp. 283$290,2016$.

[14] T. Schimmel, P. C. Johnston, and M. Stasio, "Can" Collegiality" Be Measured?: Further Validation of a Faculty Assessment Model of Discretionary Behaviors," Research in Higher Education Journal, vol. 21, 2013.

[15] A. M. Clark and B. J. Sousa, "Definitively unfinished: Why the growth mindset is vital for educators and academic workplaces," Nurse Education Today, vol. 69, pp. 26-29, 2018.

[16] J. Hunzicker, "Attitude has a lot to do with it: Dispositions of emerging teacher leadership," Teacher Development, vol. 17, no. 4, pp. 538-561, 2013.

[17] M. A. Moriarty, "Inclusive pedagogy: Teaching methodologies to reach diverse learners in science instruction," Equity \& Excellence in Education, vol. 40, no. 3, pp. 252-265, 2007. 
[18] E. A. Canning, K. Muenks, D. J. Green, and M. C. Murphy, "STEM faculty who believe ability is fixed have larger racial achievement gaps and inspire less student motivation in their classes," Science advances, vol. 5, no. 2, p. eaau4734, 2019.

[19] M. S. Wertz, M. Nosek, S. McNiesh, and E. Marlow, "The composite first person narrative: Texture, structure, and meaning in writing phenomenological descriptions," International journal of qualitative studies on health and well-being, vol. 6, no. 2, p. 5882, 2011.

[20] R. Willis, "The use of composite narratives to present interview findings," Qualitative Research, pp. 471-480., 2018.

[21] D. Layder, Structure, Interaction and Social Theory (RLE Social Theory). Routledge, 2014.

[22] D. G. Oliver, J. M. Serovich, and T. L. Mason, "Constraints and opportunities with interview transcription: Towards reflection in qualitative research," Social forces, vol. 84, no. 2, pp. 1273-1289, 2005.

[23] R. D. Hatfield, "Collegiality in higher education: Toward an understanding of the factors involved in collegiality," Journal of Organizational Culture, Communications and Conflict, vol. 10, no. 1, pp. 11-19, 2006. 